\title{
A Longitudinal Study of Adolescents' Pornography Use Frequency, Motivations, and Problematic Use Before and During the COVID-19 Pandemic
}

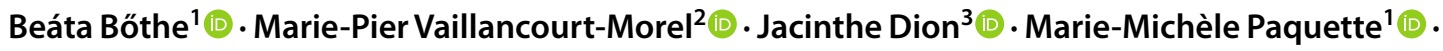 \\ Maude Massé-Pfister ${ }^{1} \cdot$ István Tóth-Király ${ }^{4}$ (i) $\cdot$ Sophie Bergeron ${ }^{1}$ (i)
}

Received: 16 December 2020 / Revised: 4 December 2021 / Accepted: 22 December 2021 / Published online: 20 January 2022

(c) The Author(s), under exclusive licence to Springer Science+Business Media, LLC, part of Springer Nature 2022

\begin{abstract}
Since the beginning of the COVID-19 pandemic, an increase in pornography use has been reported based on cross-sectional findings, raising concerns about associated adverse outcomes, such as problematic pornography use (PPU). The aims of the present study were to document potential changes in adolescents' pornography use frequency, motivations, and PPU before and during the COVID-19 pandemic. As part of an ongoing study on adolescents' sexual health, we used a large sample $\left(N_{\text {Time }}=1771\right.$; $47.6 \%$ girls, $M_{\text {age }}=15.42$ years, $S D=0.59$ ) to examine changes from baseline (before the COVID-19 pandemic) to one year later (during the COVID-19 pandemic) in adolescents' self-reported pornography use frequency, motivations, and PPU, using latent change models and examining potential gender differences. No significant changes were observed in adolescents' pornography use frequency and pornography use motivations, and no gender differences were present in these trends. Although statistically significant, slight decrease was observed in boys' PPU levels, and a statistically significant, slight increase was observed in girls' PPU levels, these changes were very small, providing no practical or clinical relevance. In sum, despite previous propositions, concerns, and cross-sectional findings, longitudinal results suggest that adolescents' pornography use characteristics were rather stable between November 2019 and June 2021, and the COVID-19 pandemic and related lockdowns might not have led to general increases in adolescents' pornography use as it was expected.
\end{abstract}

Keywords Adolescents $\cdot$ COVID-19 $\cdot$ Motivation $\cdot$ Problematic pornography use $\cdot$ Pornography

\section{Introduction}

Pornography use is not only prevalent among adults (Bőthe et al., 2018; Grubbs et al., 2019a, b, c, 2020; Herbenick et al., 2020; Lewczuk et al., 2020), but among adolescents as well (Bőthe et al., 2019; Owens et al., 2012; Peter \& Valkenburg,

Beáta Bőthe

beata.bothe@umontreal.ca

1 Department of Psychology, Université de Montréal, C.P. 6128, Succursale Centre-Ville, Montréal, QC H3C 3J7, Canada

2 Département de Psychologie, Université du Québec à Trois-Rivières, Trois-Rivières, QC, Canada

3 Intersectoral Center for Sustainable Health, Université du Québec à Chicoutimi, Chicoutimi, QC, Canada

4 Substantive-Methodological Synergy Research Laboratory, Department of Psychology, Concordia University, Montreal, QC, Canada
2016; Price et al., 2016). Based on data from nationally representative and large-scale adolescent studies from the US, Canada, and Europe (Bőthe et al., 2020b; Lobe et al., 2011; Wolak et al., 2007; Wright et al., 2020), 63 to $68 \%$ of adolescents reported lifetime, and 23 to $42 \%$ reported past-year pornography use. Since the beginning of the COVID-19 pandemic, an increase in pornography use has been documented among adults and adolescents as well in cross-sectional studies (Lehmiller et al., 2020; Li et al., 2020a, b; Nelson et al., 2020; Zattoni et al., 2020), raising questions about potential adverse health consequences (Mestre-Bach et al., 2020), such as problematic pornography use (PPU; repetitive, uncontrollable pornography use causing significant distress and functional impairment; Bőthe et al., 2020b; Kraus et al., 2018).

The COVID-19 pandemic and associated social distancing and national lockdown measures have led to adolescents' elevated levels of stress and negative emotions (Duan et al., 2020; Ellis et al., 2020; Fegert et al., 2020; Racine et al., 2020; Wang et al., 2020; World Health Organization, 2020). Previous 
studies showed that using pornography to cope with distressing emotions (e.g., emotional avoidance) was associated with higher levels of PPU (Bőthe et al., 2021a, 2021c; Wéry \& Billieux, 2016). Thus, adolescents might use pornography more frequently to cope with their COVID-19-related negative feelings, which might also be associated with higher levels of PPU (Bôthe et al., 2021 a; Wéry \& Billieux, 2016). Thus, the aim of the present study was to examine the potential role of the COVID-19 pandemic in adolescents' pornography use. Specifically, we examined longitudinal changes in adolescents' pornography use frequency, pornography use motivations, and PPU before and during the COVID-19 pandemic.

\section{COVID-19 Pandemic and a Potential Increase in Pornography Use}

In March 2020, the World Health Organization declared the COVID-19 outbreak a global pandemic (World Health Organization, 2020). The health risk and related restrictions (e.g., lockdown, social distancing, quarantine, school closures) generated a unique and unprecedented situation, resulting in increased stress levels and potential mental health issues among adults and adolescents (Duan et al., 2020; Ellis et al., 2020; Fegert et al., 2020; Islam et al., 2020; Mazza et al., 2020; Racine et al., 2020; Salari et al., 2020; Wang et al., 2020; World Health Organization, 2020). As adolescence is a time of transition toward adulthood with an increased need for autonomy (McElhaney et al., 2009) and a greater reliance on peers for social support (Smetana et al., 2006), the potential effects of restrictions and related stress may be heightened among this group (Findlay \& Arim, 2020; Racine et al., 2020).

The COVID-19-related restrictions have also resulted in more time spent at home and were expected to lead to more intense engagement in online activities (Guessoum et al., 2020). Indeed, an increase in online and screen-based activities among adolescents has been documented in the literature, including more frequent internet use, social media use, and pornography use (Duan et al., 2020; Ellis et al., 2020; Munasinghe et al., 2020; Nelson et al., 2020). Preliminary findings based on retrospective self-report (e.g., whether they watched less, more, or the same amount of pornography since the pandemic) suggest that 5 to $23 \%$ of adolescents and young adults aged between 14 and 35 years reported an increase in their pornography use since the beginning of the pandemic (Li et al., 2020a, b; Nelson et al., 2020). Moreover, an increase has been reported in the frequency of engaging in online sexual activities (including pornography) in adolescent boys, but not girls, during the COVID-19 confinements in Spain. Among the reasons for the increase, adolescents mentioned using online sexual activities to alleviate boredom, relax, or satisfy sexual needs (Nebot-Garcia et al., 2020). However, no prior study has directly examined changes in pornography use before and during the pandemic among adolescents, using longitudinal data.
To the best of the authors' knowledge, only one study reported changes in pornography use before and during the COVID-19 pandemic in adults using longitudinal data (Grubbs et al., 2021). Following a large nationally representative sample of US adults (baseline $N=2500$ ) between August 2019 and October 2020, the study documented potential changes in pornography use frequency and PPU, considering psychological distress, and potential gender differences. Findings suggest that pornography use frequency decreased in the examined 15 months in men and women as well, while PPU slightly decreased in men and remained low and stable in women. Nevertheless, it is important to note that a spike in pornography use frequency was observed in May 2020, when 14\% of the participants reported an increase in their pornography use. Still, 66\% of the participants did not report any changes, and $20 \%$ reported decreased pornography use at that time (Grubbs et al., 2021).

\section{Pornography Use Frequency, Pornography Use Motivations, and Problematic Pornography Use among Adolescents}

On average, adolescents who use pornography reported viewing it once a week or more in the past three or six months (Bôthe et al., 2020a, b; Rousseau et al., 2021). Important gender and sexual orientation-based differences were observed, as boys reported weekly or more frequent pornography use, whereas girls reported monthly or less frequent pornography use. Moreover, while heterosexual and sexually diverse boys' pornography use characteristics were similar, sexually diverse girls used pornography more frequently (once a month) than their heterosexual peers (less than once a month) (Bôthe et al., 2020b). Although a high ratio of adolescents in industrialized countries use pornography and use it relatively frequently, most of them appear to engage in pornography use without reporting any negative impact on their lives or related distress (Efrati, 2020; Kohut \& Štulhofer, 2018; Štulhofer et al., 2020). Nevertheless, 5 to $14 \%$ of adolescents who have used pornography before report excessive, compulsive, or problematic use of pornography, with boys reporting higher levels of PPU than girls in general (Bôthe et al., 2021d; Efrati \& Dannon, 2019; Efrati \& Gola, 2018; Pizzol et al., 2016; Štulhofer et al., 2020; Svedin et al., 2011).

Yet, it is important to note that pornography use in general, or even frequent pornography use, may not be considered problematic in itself (Bőthe et al., 2020a, b; Grubbs et al., 2019a, b, c; Kraus \& Sweeney, 2019; Vaillancourt-Morel et al., 2017). Motivations underlying pornography use, such as coping with negative emotions (Bőthe et al., 2021d), and out-of-control or compulsive use (i.e., PPU; Bôthe et al., 2018; Kraus et al., 2020) should also be considered when examining pornography use characteristics in adolescents, as the context of pornography use (e.g., pornography use motivations) may also play an essential role in favorable and less optimal outcomes (Bőthe et al., 2021a, 2021c; Campbell \& Kohut, 2017). 
Several motivations may underlie one's pornography use (Bőthe et al., 2019, 2021a, 2021c; Reid et al., 2011; Romito \& Beltramini, 2011; Ševčíková \& Daneback, 2014; Wéry \& Billieux, 2016), including sexual pleasure (i.e., to increase sexual arousal or help masturbation), sexual curiosity (i.e., to seek information and learn about sexuality), emotional distraction and suppression (i.e., to cope with negative emotions), stress reduction (i.e., to reduce stress), boredom avoidance (i.e., to reduce boredom), fantasy (i.e., to escape from the real world and fantasize about being part of pornography), lack of sexual satisfaction (i.e., as a result of not being satisfied with or missing something from one's sexual life), and self-exploration (i.e., to identify one's sexual needs and preferences). Although sexual pleasure is the most common motivation for pornography use in adults and adolescents as well (Bôthe et al., 2019; Grubbs et al., 2019a, b, c), pornography is also often used to alleviate boredom or cope with negative emotions or stress (Bôthe et al., 2019, 2021a; Grubbs et al., 2019a, b, c; Reid et al., 2011; Wéry \& Billieux, 2016). Thus, given reported increases in stress and potential mental health issues among adolescents since the beginning of the COVID-19 pandemic (Duan et al., 2020; Ellis et al., 2020; Fegert et al., 2020; Racine et al., 2020) and preliminary cross-sectional findings (Nebot-Garcia et al., 2020), it may be assumed that coping-related pornography use motivations might have increased during the pandemic.

Moreover, a recent longitudinal study in adolescent boys (aged between 14 and 18 years) showed that adolescents' higher levels of depressive and anxiety symptoms were associated with their higher levels of PPU (Rousseau et al., 2021). Therefore, it may be assumed that as adolescents may experience greater psychological distress during the COVID-19 pandemic (Duan et al., 2020; Ellis et al., 2020; Fegert et al., 2020; Racine et al., 2020), they may also experience higher levels of PPU.

\section{Aims of the Present Study}

Given that prior studies assessed the subjective perception of changes in adolescents' pornography use via retrospective selfreport, and not actual changes in use before and during the pandemic (Li et al., 2020a, b; Nebot-Garcia et al., 2020; Nelson et al., 2020), the aim of the present study was to document longitudinal changes in adolescents' pornography use frequency, pornography use motivations, and PPU before and during the COVID-19 pandemic. We hypothesized that adolescents might report higher levels of pornography use frequency, greater emotional distraction and suppression, boredom avoidance, and stress reduction pornography use motivations, and higher levels of PPU over time. As important differences between boys and girls' pornography use have been documented in the literature (Bőthe et al., 2019, 2021a, d; Peter \& Valkenburg, 2016), we examined potential changes in pornography use separately by gender.
As selective attrition may be present in longitudinal studies examining pornography use among adolescents, and vulnerable adolescents may be more prone to drop out from longitudinal studies, we included family environment, sexual orientation, and age at first pornography use as control variables in our longitudinal analyses (Štulhofer et al., 2021). Given that pornography use most often occurs in conjunction with masturbation, and recently, researchers have emphasized the importance of ruling out the role of this potential third variable when examining pornography use (Perry, 2019; Prause, 2019), we controlled for masturbation frequency as well. Lastly, similarly to previous longitudinal work on pornography use changes during the COVID-19 pandemic (Grubbs et al., 2021), psychological distress (i.e., COVID-19-related stress) was also accounted for in the analyses. Nevertheless, considering recent calls highlighting shortcomings of using control variables in pornography use studies (Wright, 2021), we reported our findings with and without the inclusion of control variables for full transparency.

\section{Method}

\section{Participants}

The baseline (T1) sample consisted of 1771 adolescents ( $M_{\text {age }}=15.42$ years, $S D=0.59$, age range: 14 to 18 years old), including participants who completed the survey before the COVID-19 pandemic. As for gender identity, $51.9 \%$ identified as boy $(n=608), 47.6 \%$ identified as girl $(n=557), 0.3 \%$ identified as non-binary, gender fluid or something else (e.g., genderqueer; $n=4$ ), and $0.2 \%$ identified with another cultural gender minority identity (e.g., two-spirit) $(n=2)$. The majority of participants reported being heterosexual $(85.7 \% ; n=1004), 4.1 \%$ of the participants reported questioning their sexual orientation $(n=48)$, $3.0 \%$ reported being bisexual $(n=35), 1.5 \%$ pansexual $(n=17)$, $1.1 \%$ heteroflexible $(n=13), 0.9 \%$ gay or lesbian $(n=10), 0.1 \%$ queer $(n=1), 0.1 \%$ asexual $(n=1), 0.1 \%$ homoflexible $(n=1)$, $2.2 \%$ selected the "none of the above" answer option $(n=26)$, and $0.9 \%$ did not want to answer this question $(n=11)$.

The follow-up (T2) sample consisted of 899 adolescents ( $M_{\text {age }}=16.43$ years, $S D=0.55$, age range: 15 to 18 years old), including participants who completed the survey during the COVID-19 pandemic. As for gender identity, $48.3 \%$ identified as boy $(n=434), 50.8 \%$ identified as girl $(n=457), 0.7 \%$ identified as non-binary, gender fluid or something else (e.g., genderqueer; $n=6$ ), $0.1 \%$ identified with another cultural gender minority identity (e.g., two-spirit) $(n=1)$, and $0.1 \%$ selected the "other" answer option $(n=1)$. The majority of participants reported being heterosexual $(83.9 \% ; n=754)$, $4.8 \%$ reported being bisexual ( $n=43), 4.1 \%$ of the participants reported questioning their sexual orientation $(n=4837), 1.7 \%$ pansexual $(n=15), 1.2 \%$ heteroflexible $(n=11), 1.6 \%$ gay or lesbian $(n=14), 0.3 \%$ queer $(n=3), 0.1 \%$ asexual $(n=1), 0.1 \%$ 
homoflexible $(n=1), 1.0 \%$ selected the "none of the above" answer option $(n=9)$, and $1.1 \%$ did not want to answer this question $(n=10)$.

\section{Procedure}

Data were collected during the second and third waves of a large, ongoing bi-center Canadian longitudinal study on adolescents' sexual health that began in 2018 (all measures assessed in the larger project can be found at https://osf.io/gy9wp/?view_ only $=\mathrm{d} 862 \mathrm{f} 3 \mathrm{ceb} 79 \mathrm{a} 447 \mathrm{a} 946513267839 \mathrm{c} 75 \mathrm{f}$ ). Participants from different socioeconomic backgrounds, and Caucasian and multi-ethnic populations attending tenth grade were recruited through their high schools from large metropolitan and rural areas. Out of the 23 schools that completed the first data collection wave, ten participated in the second data collection wave before the COVID-19 pandemic, and in the one-year follow-up. As the variables used in the present study were only assessed at the second and third data collection waves, we will refer to these data collection points as Time 1 (baseline, T1) and Time 2 (follow-up, T2) in the following sections of the paper.

Baseline (T1) data collection took place between November 2019 and March 11, 2020 (i.e., before the COVID-19 pandemic), while the one-year follow-up (T2) data collection took place between October 2020 and June 2021 (i.e., during the COVID-19 pandemic). Although schools were closed in the province of Quebec (Canada) in the spring of 2020, they reopened in September 2020, and all participating high schools agreed to an in-class data collection. In line with recommended COVID-19 safety measures, our team modified the study procedure. Namely, we developed mitigation strategies, including a medical form that needed to be completed by research assistants before data collection, the use of face covers, hand-washing, and disinfection of all materials between data collection in different classes (e.g., electronic tablets).

During the T1 data collection, 1215 students were approached, and a participation rate of $99.1 \%$ was reached (10 students refused to participate, and one withdrew from the study). Out of the 1204 participants who agreed to participate, 31 participants were excluded because they failed at least two out of the three attention-testing questions. Two participants were excluded because of inconsistent response patterns, resulting in a final sample of 1171 participants in T1. During the T2 data collection, 1149 students were approached, and a participation rate of $98.3 \%$ was reached (20 students refused to participate). Out of the 1129 participants who agreed to participate, 272 students' T1 and T2 data could not be matched (either as a result of failing the attention testing questions or non-matching IDs), resulting in a final sample of 899 participants in $\mathrm{T} 2$.

To complete the online self-reported survey through the secure platform Qualtrics Research Suite, two trained research assistants visited each class, presented the aims of the study, and distributed electronic tablets to all participants, who provided informed consent before completing the survey. ${ }^{1}$ Three additional attention-testing questions were also embedded in the survey. If students failed at least two out of these questions, their data were considered invalid (Thomas \& Clifford, 2017). At the end of the 30 to 45 -min survey completion, a CDN\$10 gift card was given as compensation. Ethical approval was granted by the ethics committee of the two related universities and the relevant school boards, and the study was carried out under the Declaration of Helsinki.

\section{Measures}

\section{Gender}

Gender was measured using the following question (Bauer et al., 2017): "What gender or gender identity do you identify with?" The answer options were masculine/boy; feminine/girl; other cultural gender minority identity (e.g., two-spirit); nonbinary, gender fluid or something else (e.g., genderqueer); and other (with specification). To increase the statistical power and simplify the analysis, we created three groups based on gender reported in T1 data collection: those adolescents who reported being masculine/boy $(n=608 ; 51.9 \%)$ were included in the boys group, those who reported being feminine/girl $(n=557,47.6 \%)$ were included in the girls group, and those who reported being other cultural gender minority identity (e.g., two-spirit); nonbinary, gender fluid or something else (e.g., genderqueer); or chose the "other" answer option $(n=6,0.5 \%)$ were included in the non-binary adolescents group. ${ }^{2}$

\section{Sexual Orientation}

Sexual orientation was measured with one item based on prior recommendations (Weinrich, 2014): "People describe their sexual orientation in different ways. Which expression best describes your current sexual orientation? If no expression describes you, check "None of the above" and write the answer that describes you personally."; answer options were straight; I do not know yet, or I am currently questioning my sexual orientation; gay or lesbian or homosexual; heteroflexible; homoflexible; bisexual; queer; pansexual; asexual; none of the above; I don't want to answer; other (with specification).

To simplify the statistical analysis and increase statistical power, we created two groups based on sexual orientation

\footnotetext{
${ }^{1}$ In Quebec (Canada), adolescents can provide their own informed consent from age 14. Not relying on parental consent can ensure the safety of students involved in the study and can prevent sampling biases that may distort the results.

${ }^{2}$ Given the small sample size in the non-binary group, when we could not compare their group to the boys' and girls' groups statistically, we provided descriptive statistics for them.
} 
reported in T1 data collection: Those adolescents who reported being heterosexual $(n=1004,85.7 \%)$ were included in the heterosexual group; those who were questioning their sexual orientation; were gay or lesbian; heteroflexible; homoflexible; bisexual; queer; pansexual; or chose the "none of the above" option ( $n=154,13.2 \%)$ were included in the sexually diverse group, and 13 adolescents (1.1\%) did not report their sexual orientation and thus were not included in either group.

\section{Family Environment}

Adolescents' family environment was measured with one item: "Who do you live with most of the time?"; answer options were with my mother and my father; with my two mothers; with my two fathers; with my mother only; with my mother and her partner; with my father only; with my father and his partner; as much with one parent as with the other; other (guardian, family or foster home, alone, with a roommate, etc.) (with specification). To simplify the statistical analysis and increase statistical power, we created two groups based on family environment reported in $\mathrm{T} 1$ data collection: Those adolescents who reported living with their mother and father; their two mothers; or their two fathers $(n=840,71.7 \%)$ were included in the living with both parents group; and those who reported living with their mother only; their mother and her partner; their father only; their father and his partner; living as much with one parent as with the other; or other (guardian, family or foster home, alone, with a roommate, etc.) option $(n=331,28.3 \%)$ were included in the other living situation group.

\section{Masturbation Frequency}

Before answering any masturbation-related questions, participants read the following definition: "For the following questions, "masturbation" refers to seeking sexual pleasure by self-stimulation of the genitals (i.e., by oneself), either by manual caresses, sex toys, rubbing, pressure or any other technique. Masturbation may or may not lead to an orgasm.". First, adolescents were asked about lifetime masturbation: "Do you masturbate?" $(0=n o ; 1=y e s)$. For those who answered "yes," the frequency of masturbation in the past three months was assessed through the following question: "On average, over the past three months, how often did you masturbate?'. Participants indicated their responses on an eight-point scale $(1=$ not once in the past three months; $8=$ more than once a day). Based on the lifetime masturbation and frequency of masturbation variables, we computed a new masturbation frequency score for $\mathrm{T} 1$ and $\mathrm{T} 2$ as well. We recoded the responses of those adolescents who indicated that they had not masturbated before (i.e., answering "no" to the lifetime masturbation question; T1: $n=348,29.7 \%$; T2: $n=227,19.4 \%$ ) to represent "never" in the masturbation frequency question. We used the new masturbation frequency variables in further analyses.

\section{Age at First Pornography Use}

Before answering any questions related to pornography use, participants read the following definition (Kohut et al., 2018, 2020): "For the following questions, the term 'pornography' is used to refer to intentionally looking at or listening to (1) pictures or videos of nude individuals, (2) pictures or videos in which people are having sexual activities." First, adolescents answered one question about their lifetime pornography use ("Have you ever watched pornography in your life?"; $0=n o$; $1=y e s)$. If they had viewed pornography in their lifetime, they were asked to report their age at first use ("How old were you the first time you watched pornography?").

\section{Pornography Use Frequency}

Past three months pornography use frequency was assessed with one item, using an eight-point scale: "On average in the last three months, how many times did you watch pornography?; $0=$ never; $7=$ many times per day." Based on the responses to the lifetime pornography use and frequency of pornography use variables, we computed a new pornography use frequency variable for $\mathrm{T} 1$ and $\mathrm{T} 2$ as well. We recoded the responses of those adolescents who indicated that they had not used pornography previously (i.e., answering "no" to the lifetime pornography use question; T1: $n=333,28.4 \%$; T2: $n=234,20.0 \%$ ) to represent "never" in the pornography use frequency question. We used the new pornography use frequency variables in further analyses.

\section{Pornography Use Motivations}

To assess the motivations underlying participants' pornography use in T1 and T2 as well, we used the short, eight-item version of the Pornography Use Motivations Scale (PUMS; Bôthe et al., 2021a) and adapted it to the adolescent population. Each item represented one motivation: sexual pleasure ("I watch porn because it makes masturbation easier"), sexual curiosity ("I watch porn to learn new things"), fantasy ("I watch porn because it provides such an experience that would be impossible in real life"), lack of sexual satisfaction ("I watch porn because I am not content with my sexual life"), boredom avoidance ("I watch porn because I want to pass time when I am bored"), emotional distraction and suppression ("I watch porn because it makes me forget my problems"), stress reduction ("I watch porn because it calms me down"), and self-exploration ("I watch porn because I can find out what turns me on"). Participants indicated their answers on a seven-point scale $(1=$ never $; 7=$ all the time). Only participants who reported lifetime pornography use could complete the PUMS. Those participants' naturally "missing" answers who did not use pornography in their life (T1: $n=333,28.4 \%$; T2: $n=234,20.0 \%$ ) were recoded as "never" on all PUMS' items for further analyses. 


\section{Problematic Pornography Use}

Participants' PPU was measured in $\mathrm{T} 1$ and $\mathrm{T} 2$ as well using the short, six-item version of the Problematic Pornography Consumption Scale (Bőthe et al., 2021b), which has been adapted for adolescents (PPCS-6-A; Bôthe et al., 2021d). The PPCS6-A assesses PPU with six items regarding the past six months (e.g., "When I promise myself not to watch porn anymore, I can only stop for a short time"). Each item represents one component of Griffiths' six-component model of addiction (i.e., salience, tolerance, mood modification, relapse, withdrawal, and conflict; Bôthe et al., 2018; Griffiths, 2005). Adolescents indicated their answers on a seven-point scale $(1=$ never $; 7=$ all the time); higher scores indicate higher levels of PPU. The scale demonstrated good reliability in the present study $\left(\alpha_{\mathrm{T} 1}=0.81\right.$, $\left.\alpha_{\mathrm{T} 2}=0.83\right)$. Only participants who reported lifetime pornography use could complete the PPCS-6-A. Those participants' naturally "missing" answers who did not use pornography in their life (T1: $n=333,28.4 \%$; T2: $n=234,20.0 \%$ ) were recoded as "never" on all PPCS-6-A's items for further analyses.

\section{COVID-19-Related Stress}

We used one question to assess COVID-19-related stress in T2: "How would you rate the amount of stress in your life related to COVID-19?" Participants indicated their answers on a six-point scale $(1=$ no stress $; 6=$ extreme stress $)$.

\section{Statistical Analyses}

\section{Descriptive Analyses and Attrition Analyses}

Descriptive statistics, Cronbach's alphas, normality indices (i.e., skewness and kurtosis values), correlations, and attrition analysis were computed in SPSS 25. In the attrition analysis, two groups (adolescents who completed the $\mathrm{T} 2$ survey vs. who did not complete the T2 survey) were compared in their T1 sociodemographic characteristics (i.e., gender, sexual orientation, family environment), age at first pornography use, levels of pornography use frequency, pornography use motivations, and PPU, using chi-square, independent samples $t$ tests, and Mann-Whitney $U$ tests (in cases when the assumptions of independent samples $t$ tests were not met). To increase statistical power, in all analyses when the role of gender, sexual orientation, and family environment were examined, we used dichotomized variables based on $\mathrm{T} 1$ data (gender: $0=$ boys, $1=\operatorname{girl}^{3}$; sexual orientation: $0=$ heterosexual, $1=$ sexually diverse; family environment: $0=$ living with both parents, $1=$ other living situation).

\section{Model Estimation}

Analyses focusing on examining change over time were conducted using Mplus 8.2 (Muthén \& Muthén, 2018). First, we examined the psychometric properties of the multi-item measure of PPU and tested its measurement invariance over time (Millsap, 2011) to obtain longitudinally invariant factor scores for the main analyses. Relying on factor scores (instead of more traditional averaged or summed scores) was based on the fact that factor scores are better at preserving the measurement properties of the scales (i.e., invariance; Morin et al., 2016) and maintaining some level of control for unreliability (Skrondal \& Laake, 2001). For these preliminary analyses, we used Mplus' robust weight least square estimator with mean and variance adjusted statistics (WLSMV) as this estimator is designed to handle ordinal rating scales following asymmetric response thresholds (Finney \& DiStefano, 2013; Morin et al., 2019).

\section{Specification}

The longitudinal measurement invariance models underpinning PPU were estimated using a confirmatory factor analytic (CFA) approach in which items were loaded on their latent factor. These tests of measurement invariance were conducted in the following sequence (Millsap, 2011): (1) configural invariance (i.e., the same factor structure); (2) weak invariance (i.e., invariance of factor loadings); (3) strong invariance (i.e., invariance of factor loadings and thresholds); and (4) strict invariance (i.e., the invariance of factor loadings, thresholds, and uniquenesses). Due to the nature of the latent change model, in which the factor means and variances need to be freely estimated in order to be able to detect change over time, we pursued tests of measurement invariance up to the level of strict measurement invariance, which allowed the free estimation of these parameters while, at the same time, ascertaining stable measurement. A priori correlated uniquenesses were added between matching indicators over time to avoid inflated stability estimates (Marsh, 2007). Finally, given the theoretical and empirical distinctiveness of boys and girls' pornography use characteristics, we estimated all models separately for boys and girls.

\section{Model Fit}

Common goodness-of-fit indices were used to assess the adequacy of the measurement models (Marsh et al., 2005): the comparative fit index (CFI), the Tucker-Lewis Index (TLI), and the root-mean-square error of approximation (RMSEA). CFA and TLI are considered good or excellent when values are

\footnotetext{
${ }^{3}$ Given the small sample size in the non-binary group, we could not compare their group to the boys' and girls' groups statistically, but we provided descriptive statistics for them.
} 
higher than 0.90 and 0.95 , respectively. In contrast, RMSEA is considered good or excellent when values are smaller than 0.08 and 0.06 , respectively. The chi-square test $\left(\chi^{2}\right)$ is also reported for the sake of transparency, but it is not considered in model evaluations as this indicator is oversensitive to high sample size and minor model misspecification (Marsh et al., 2005). In the context of measurement invariance, the focus is on the relative changes $(\Delta)$ in the fit indices: a $\Delta$ CFI of 0.010 or less, a $\Delta$ TLI of 0.010 or less, and a $\triangle$ RMSEA of 0.015 or less suggests that invariance has been achieved (Chen, 2007; Cheung \& Rensvold, 2002). Model-based composite reliability indices (McDonald, 1970; Morin et al., 2019) were also calculated using the standardized factor loadings and the error variances associated with the items.

\section{Longitudinal Latent Change Analyses}

Longitudinal latent change analyses (McArdle, 2008) were realized to assess changes in pornography use frequency, pornography use motivations, and PPU over time using Mplus' robust maximum likelihood (MLR) estimator. Latent change models allowed us to disaggregate the repeated measures into their initial levels (the $\mathrm{T} 1$ scores) and a latent change factor representing change (growth, decline, or stability) occurring between $\mathrm{T} 1$ and T2. These models were specified by (e.g., Tóth-Király et al., 2020): (1) regressing the $\mathrm{T} 2$ scores on the $\mathrm{T} 1$ score and fixing this regression path to be exactly 1 ; (2) estimating latent change factors defined by the $\mathrm{T} 2$ score and fixing the factor loading of this score on the latent change factor to be exactly 1 ; (3) fixing the intercept and residual of the $\mathrm{T} 2$ scores to be exactly zero in order to freely estimate the means and variances of the latent change factors; and (4) allowing the initial level to freely correlate with the latent change factors. Given that this latent change model is just identified (as in multivariate regressions), model fit was necessarily perfect and will not be reported. Separate latent change models were estimated for all three sets of variables (i.e., pornography use frequency, pornography use motivations, and PPU) for boys and girls. In addition, we examined change without and with the inclusion of controls (i.e., sexual orientation, family environment, masturbation frequency, age at first pornography use, and COVID-19-related stress), which were simply regressed on the $\mathrm{T} 1$ and latent change scores. The de-identified data and analyses materials used in the present study can be obtained from https://osf.io/849hz/?view_only= 7d632791efa44755b4f913b14c869710.

\section{Results}

\section{Attrition Analysis}

Out of the 1171 participants who completed the T1 data collection wave, 899 (76.8\%) participated in the T2 data collection
(Table 1). When comparing the sociodemographic, masturbation, and pornography use-related characteristics of those adolescents who completed vs. did not complete the $\mathrm{T} 2$ data collection, no significant differences were observed between these groups regarding their baseline (T1) sexual orientation, masturbation frequency, pornography use frequency, all pornography use motivations (except for lack of sexual satisfaction motivation), and PPU levels (all $p s>0.063$ ). However, a higher ratio of the adolescents who did not complete the follow-up survey (T2) were boys (completed the T2 survey: $49.4 \%$ vs. did not complete the T2 survey: $60.3 \% ; p=0.001$ ) and did not live with both parents (completed the T2 survey: $26.8 \%$ vs. did not complete the T2 survey: $33.1 \% ; p=0.044$ ), supporting these variables' inclusion in further analyses. Adolescents who did not complete the follow-up survey (T2) also started to watch pornography from a younger age (completed the $\mathrm{T} 2$ survey: $M=12.44, S D=1.76$; vs. did not complete the survey: $M=12.12, S D=1.94, p=0.033$ ); and had higher lack of sexual satisfaction pornography use motivations (completed the T2 survey: $M=1.87, S D=1.49$; vs. did not complete the survey: $M=2.23, S D=1.70, p=0.001)$ at baseline (T1).

\section{Longitudinal Measurement Invariance}

The goodness-of-fit results associated with the measurement models are reported in Table S1. These results indicate that all of these measurement models resulted in an adequate level of fit to the data (all CFI/TLI $\geq 0.90$ and all RMSEA $\leq 0.06$ ) and appeared to be fully invariant over time $(\triangle \mathrm{CFI}$ and $\Delta \mathrm{TLI} \leq 0.01$; $\triangle$ RMSEA $\leq 0.015)$. Parameter estimates from the strict invariant models are reported in Table S2 and reveal that all PPU factors were well defined and reliable across time points both for boys (Time $1: \lambda=0.71$ to $0.84, M=0.78 ; \omega=0.90$; Time 2 : $\lambda=0.75$ to $0.87, M=0.82 ; \omega=0.92$ ) and girls (Time $1: \lambda=0.85$ to $0.91, M=0.87 ; \omega=0.95$; Time $2: \lambda=0.81$ to $0.88, M=0.84$; $\omega=0.93)$.

\section{Longitudinal Changes in Adolescents' Pornography Use Characteristics Before and During the COVID-19 Pandemic by Gender}

Descriptive statistics and bivariate associations between sociodemographic characteristics (i.e., gender, sexual orientation, family environment), masturbation frequency, pornography use frequency, pornography use motivations, PPU, and COVID19-related stress in $\mathrm{T} 1$ and $\mathrm{T} 2$ are shown in Table 2 and Table 3. The results from the latent change models are reported in Table 4 for boys and Table 5 for girls. ${ }^{4}$

\footnotetext{
${ }^{4}$ Given the small sample size in the non-binary individuals group, we were not able to include them in the latent change models.
} 
Table 1 Descriptive statistics and comparisons of participants who completed vs. did not complete the follow-up (Time 2) measures in their baseline (Time 1) characteristics

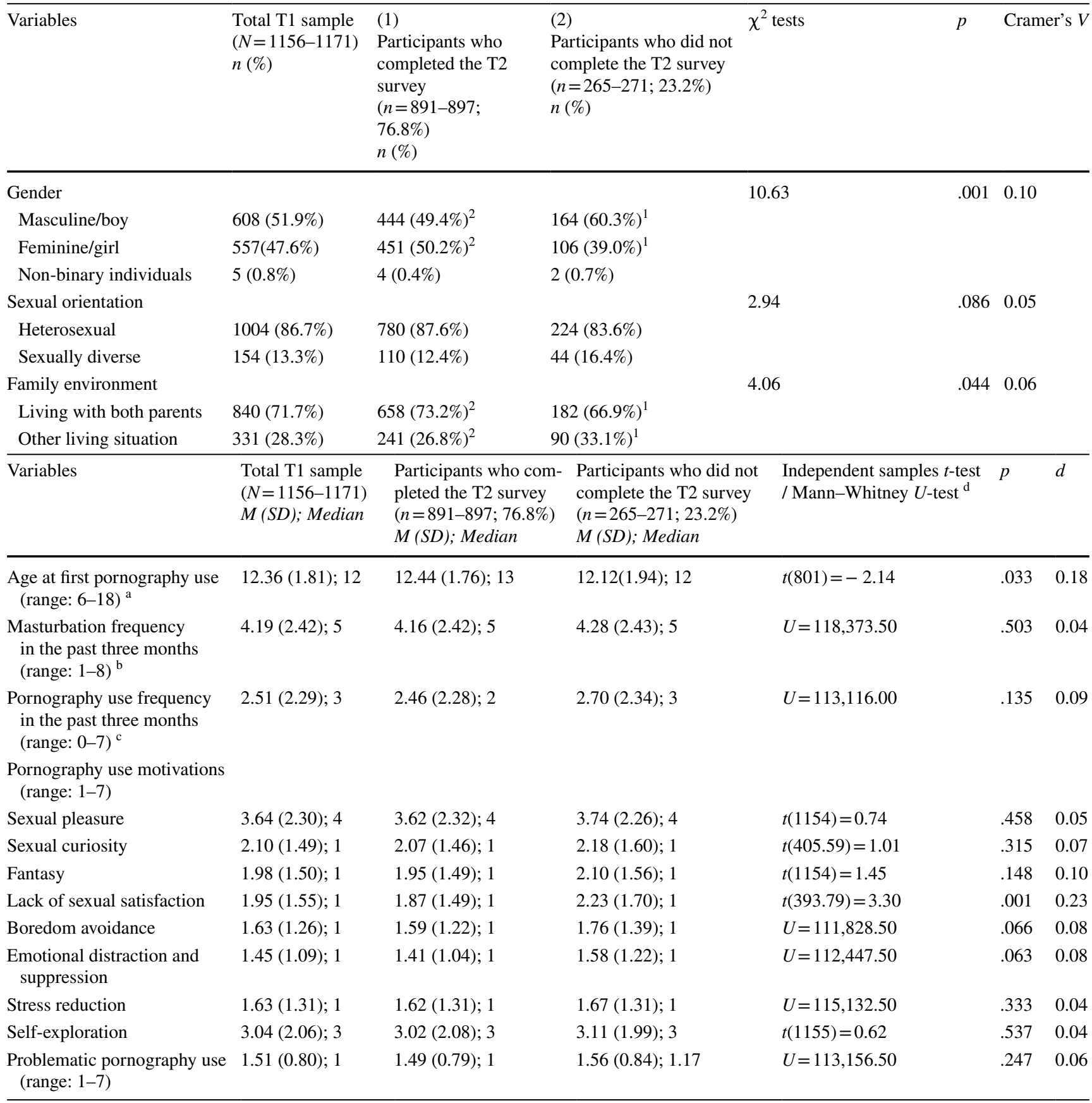

$M=$ mean; $S D=$ standard deviation; T1 = Time 1 data collection; T2 =Time 2 data collection. In the case of the $\chi^{2}$ tests, superscript numbers $(1$, $2)$ indicate significant $(p<.05)$ difference between the given group and the indexed group within the same variable

${ }^{a}$ Only those adolescents reported their age at pornography use who had watched pornography before $(n=803)$

${ }^{\mathrm{b}} 1=$ not once in the past three months; $2=$ less than once a month; $3=$ once a month; $4=$ two to three times a month; $5=$ once a week; $6=$ several times a week; $7=$ once a day; $8=$ more than once a day

${ }^{\mathrm{c}} 0=$ never, $1=$ less than 1 time per month, $2=1$ time per month, $3=2-3$ times per month, $4=1$ time per week, $5=$ many times per week, $6=1$ time per day, $7=$ many times per day

${ }^{\mathrm{d}}=$ Mann Whitney $U$-tests were used for variables that were not distributed normally and did not met the assumptions of $t$-tests 
Results revealed several noteworthy findings. Among boys, without the controls, all variables had initial levels that were significantly higher than 0 . These initials levels were accompanied by substantial level of inter-individual variability (i.e., statistically significant variance parameters associated with all initial levels), suggesting that some boys might have had a higher, whereas others might have had a lower, initial levels than the average. There was little change at the mean levels as only boys' PPU showed a slight decline over the one-year period, while the frequency of pornography use and motivations for use remained stable. At the same time, there was evidence of statistically significant variability in these changes (i.e., statistically significant variance parameters associated with the change scores). Thus, individual changes were likely to be heterogeneous, with a number of boys experiencing either significant increases or decreases during this period. The inclusion of the controls (see Table S3 in the online supplementary materials for the exact effects of the controls) did not change the results substantially, providing support for the robustness of these findings.

Girls' results were highly similar to those of the boys. More specifically, while initial levels of frequency of use and motivations for use were significantly higher than 0 , initial levels of PPU were significantly lower than 0 . Similarly, all of these initial levels were accompanied by statistically significant variance parameters. Examining the change scores revealed that pornography use frequency, PPU, and sexual pleasure, sexual curiosity, and boredom avoidance motivations slightly increased over this one-year period. However, with the inclusion of controls (see Table S4 in the online supplementary materials for the exact effect of the controls), most of these minimal increases disappeared, and only PPU demonstrated a slight, yet statistically significant increase. These results suggest that changes in the other variables (i.e., pornography use frequency, and sexual pleasure, sexual curiosity, and boredom avoidance motivations) might be explained by these controls. Still, as in the case of boys, girls' change scores were also accompanied by statistically significant variance parameters, suggesting that some girls might have experienced significant increases or decreases during this period, hence the lack of significant mean level change.

\section{Discussion}

Similar trends were observed in boys and girls' pornography use characteristics when examining potential changes before and during the COVID-19 pandemic. Despite prior studies reporting a self-perceived increase in adolescents and young adults' pornography use since the beginning of the COVID19 pandemic (Li et al., 2020a, b; Nebot-Garcia et al., 2020; Nelson et al., 2020), our results suggest that adolescents during the COVID-19 pandemic did not report using pornography more frequently and they did not engage more frequently in pornography use due to different motivations (e.g., using pornography to decrease boredom or suppress negative emotions). Moreover, in line with the findings of the only longitudinal study reporting temporal trends in PPU in adults (Grubbs et al., 2021), our results suggest that PPU slightly decreased during the COVID-19 pandemic in boys, compared to pre-COVID-19 times. Although girls' PPU levels were low before and during the COVID-19 pandemic as well, a statistically significant increase was observed in girls' PPU levels. Yet, these changes were negligible and the overall score of girls is still considered low, providing no real practical relevance.

\section{No Significant Changes in Adolescents' Pre-COVID-19 and During COVID-19 Pornography Use Frequency and Motivations}

Despite previously documented differences between adolescent boys and girls' pornography use characteristics (Bôthe et al., 2019; 2021d; Bőthe et al., 2020b; Peter \& Valkenburg, 2016), no gender differences were observed in the trends of changes in pornography use frequency and pornography use motivations. In contrast with our hypothesis and findings of prior studies among adolescents and young adults ( $\mathrm{Li}$ et al., 2020a, b; Nelson et al., 2020), adolescents during the COVID19 pandemic and related lockdowns did not show significant changes in their frequency of pornography use compared to the pre-COVID-19. On average, boys used pornography many times per week, while girls used it less than once a month both before and during the COVID-19 pandemic.

One main difference between the present study and previous ones is that we used a longitudinal study design to compare adolescents' pornography use characteristics before and during the COVID-19 pandemic, whereas past studies used samples recruited during the pandemic and asked about participants' perception concerning changes in their pornography use (e.g., whether they watched less, more, or the same amount of pornography since the pandemic; Li et al., 2020a, b; Nelson et al., 2020). Given potential recall biases in retrospective studies of online activities (Kahn et al., 2014), adolescents' reports about their pornography use before the pandemic or changes in their pornography use during the pandemic may not be as accurate as comparing actual reports on pornography use characteristics before and during the pandemic.

Another difference between previous studies ( $\mathrm{Li}$ et al., 2020a, b; Nelson et al., 2020) and the present one is related to samples' characteristics. Our study included a diverse sample of adolescents aged between 14 and 18 years (with a mean age of 15.4 years at baseline), including all genders and sexual orientations. However, two of the prior studies included both adolescents and young adults (i.e., 967 participants were aged between 15 and 35 with a mean age of 26.6 years in Li et al., 2020a, b; and 134 participants were aged between 16 and 20 with a mean age of 19.2 in Nebort-Garcia et al., 2020), while 


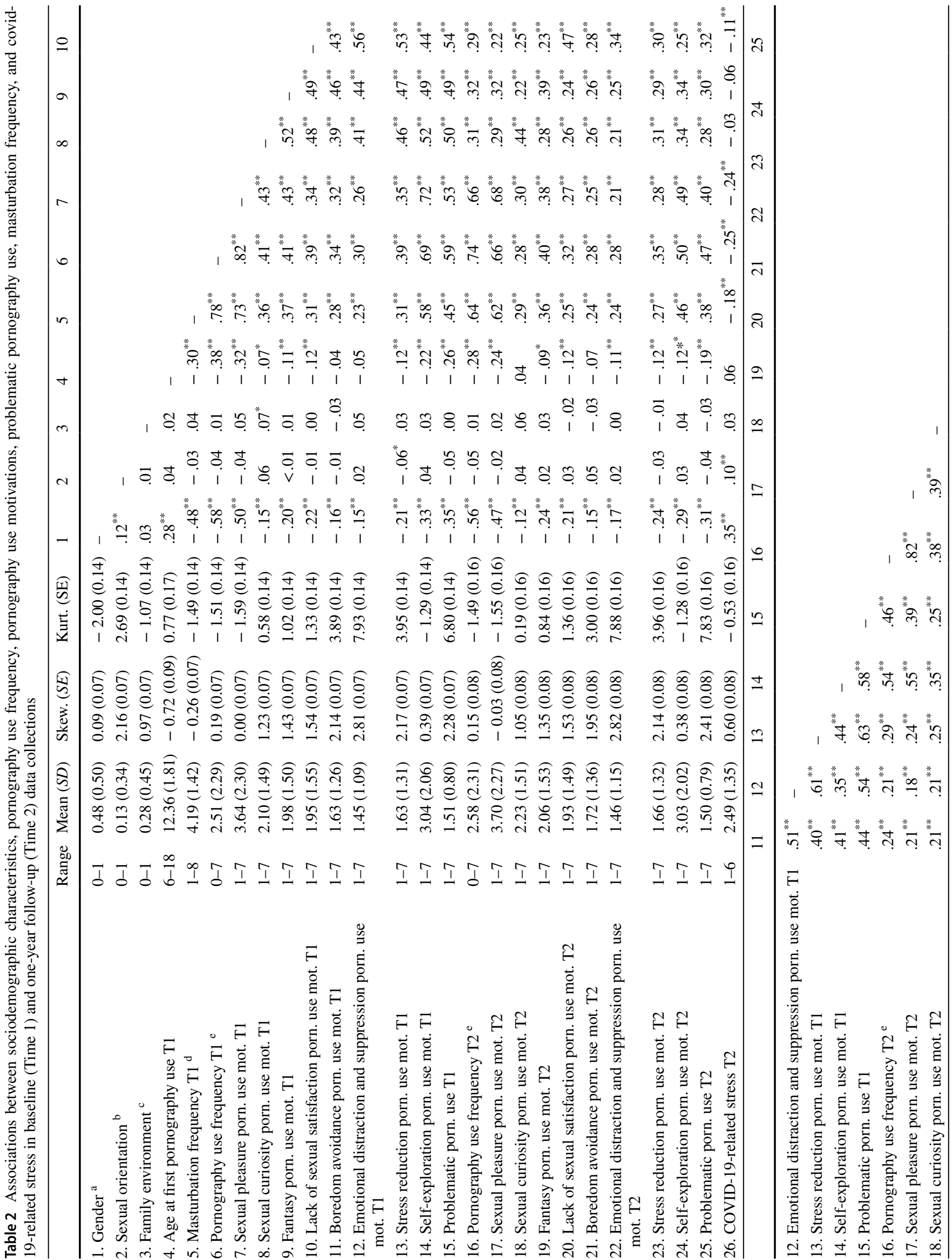




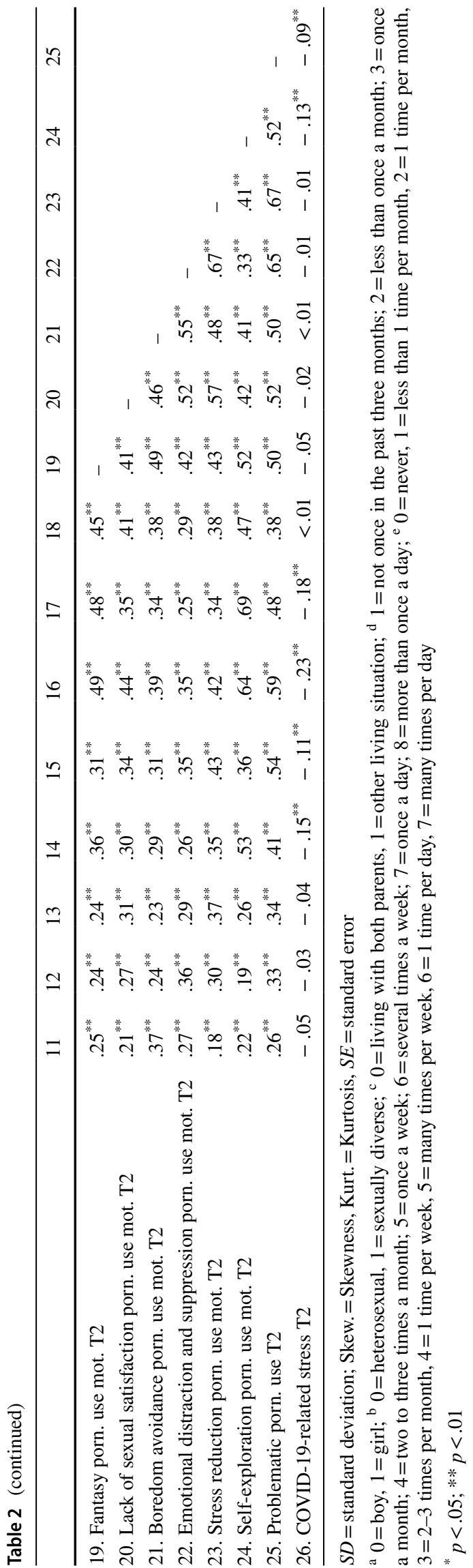

the other study focused on a more specific population of 151 adolescents, namely sexual minority boys aged between 15 and 17 years (Nelson et al., 2020). These differences in sample characteristics might have yielded different results. For example, as our sample only included adolescents, most lived with their parents. As many parents also followed COVID-19-related regulations (e.g., social distancing, closure of workplaces) and experienced shutdowns, adolescents were more likely at home with their parents, and thus, might not have more opportunities to view pornography than before, while young adults might have lived alone and worked from home during the pandemic, providing more opportunities for pornography use.

Moreover, adolescents aged between 13 and 18 years also vary in their level of engagement in social distancing, with only $30.5 \%$ of them engaging in pure social distancing (no in-person contact with those outside their household; Oosterhoff \& Palmer, 2020; Oosterhoff et al., 2020). Therefore, it is possible that adolescents spent more time with their friends in offline settings, leaving less time for engaging in online activities, including pornography use, resulting in no changes in their pornography use frequency.

Lastly, adolescents returned to a hybrid model of education (i.e., half in-class and half online) in the province of Quebec (Canada) between the fall of 2020 and summer of 2021 (i.e., when the follow-up survey was administered), which might have provided them with the opportunity to return to part of their pre-COVID-19 academic routine, resulting in the no significant changes in their long-term pornography use frequency. Still, temporary increases in pornography use might have been present among adolescents in the first months of the COVID19 pandemic (i.e., spring and summer of 2020). One of the largest pornography websites reported higher traffic on their website in Canada between March and July 2020 compared to pre-COVID-19 rates, with a peak of a $21.5 \%$ increase in pornography use on March 25, 2020 (Pornhub.com, 2020a, $2020 \mathrm{~b}$ ). These reports of increases in pornography use were also supported by a global analysis of Google search trends (Zattoni et al., 2020). Yet, in line with our findings, when a longer-term trend in pornography use frequency was examined before and during the COVID-19 pandemic among adults, individuals' use had returned to similar or even lower levels of use as reported before the pandemic by August to October 2020 (Grubbs et al., 2021). In sum, findings suggest that although a temporary increase might have been present in individuals' pornography use frequency in the first months of the COVID19 pandemic, these changes were likely transient.

Although it was proposed in the literature that pornography may be used as a potential distraction from negative emotions and stress that accompany the COVID-19 pandemic (Mestre-Bach et al., 2020), adolescents did not report significantly higher levels of emotional distraction and suppression, boredom avoidance, and stress reduction pornography use motivations during the COVID-19 pandemic, compared 
Table 3 Descriptive statistics of participants' pornography use frequency, pornography use motivations, problematic pornography use at baseline (Time 1) and one-year follow-up (Time 2) data collections by gender

\begin{tabular}{|c|c|c|c|c|c|c|c|}
\hline & \multirow[t]{2}{*}{ Range } & \multicolumn{2}{|c|}{$\begin{array}{l}\text { Boys }\left(n_{-} T 1=601-604 ; n_{-} T 2=438-\right. \\
439)\end{array}$} & \multicolumn{2}{|c|}{$\begin{array}{l}\text { Girls }\left(n_{-} T l=550-553 ; n_{-} T 2=447-\right. \\
449)\end{array}$} & \multicolumn{2}{|c|}{$\begin{array}{l}\text { Non-binary individuals }\left(n_{-T l}=5 \text {; }\right. \\
\left.n_{-T 2}=3-4\right)\end{array}$} \\
\hline & & $\begin{array}{l}\text { Time } 1 \mathrm{M}(S D) \text {; } \\
\text { Median }\end{array}$ & $\begin{array}{l}\text { Time } 2 \mathrm{M}(S D) \text {; } \\
\text { Median }\end{array}$ & $\begin{array}{l}\text { Time } 1 \mathrm{M}(S D) \text {; } \\
\text { Median }\end{array}$ & $\begin{array}{l}\text { Time } 2 \mathrm{M}(S D) \text {; } \\
\text { Median }\end{array}$ & $\begin{array}{l}\text { Time } 1 \mathrm{M}(S D) \\
\text { Median }\end{array}$ & $\begin{array}{l}\text { Time } 2 \mathrm{M}(S D) \text {; } \\
\text { Median }\end{array}$ \\
\hline $\begin{array}{l}\text { Porn. use fre- } \\
\text { quency }^{\text {a }}\end{array}$ & $0-7$ & 3.80 (2.04); 5 & 3.90 (2.07); 5 & 1.12 (1.65); 0 & 1.30 (1.74); 0 & 1.80 (2.17); 1 & 1.67 (2.08); 1 \\
\hline \multicolumn{8}{|c|}{$\begin{array}{l}\text { Pornography use motiva- } \\
\text { tions }\end{array}$} \\
\hline Sexual pleasure & $1-7$ & 4.76 (1.99); 5 & 4.77 (1.96); 5 & 2.44 (1.99); 1 & 2.65 (2.06); 1 & 2.40 (1.95); 1 & $3.25(2.22) ; 3$ \\
\hline Sexual curiosity & $1-7$ & $2.31(1.52) ; 2$ & $2.42(1.51) ; 2$ & $1.87(1.43) ; 1$ & 2.05 (1.50); 1 & $1.00(0.00) ; 1$ & $1.50(0.58) ; 1.5$ \\
\hline Fantasy & $1-7$ & $2.27(1.61) ; 1$ & $2.43(1.67) ; 2$ & $1.67(1.31) ; 1$ & 1.71 (1.28); 1 & $1.60(0.89) ; 1$ & $1.33(0.58) ; 1$ \\
\hline $\begin{array}{l}\text { Lack of sexual } \\
\text { satisfaction }\end{array}$ & $1-7$ & $2.28(1.72) ; 1$ & $2.26(1.63) ; 1$ & $1.60(1.24) ; 1$ & $1.62(1.26) ; 1$ & $1.20(0.45) ; 1$ & $1.33(0.58) ; 1$ \\
\hline $\begin{array}{l}\text { Boredom avoid- } \\
\text { ance }\end{array}$ & $1-7$ & $1.82(1.40) ; 1$ & 1.93 (1.48); 1 & 1.42 (1.05); 1 & 1.51 (1.20); 1 & 1.00 (0.00); 1 & 1.00 (0.00); 1 \\
\hline $\begin{array}{l}\text { Emotional dist. } \\
\text { and supp }\end{array}$ & $1-7$ & $1.60(1.22) ; 1$ & $1.66(1.35) ; 1$ & $1.28(0.90) ; 1$ & 1.28 (0.87); 1 & $1.20(0.45) ; 1$ & $1.00(0.00) ; 1$ \\
\hline Stress reduction & $1-7$ & 1.89 (1.49); 1 & 1.97 (1.56); 1 & $1.35(1.00) ; 1$ & $1.35(0.95) ; 1$ & $1.40(0.89) ; 1$ & $1.00(0.00) ; 1$ \\
\hline Self-exploration & $1-7$ & $3.70(2.01) ; 4$ & 3.62 (1.98); 4 & $2.33(1.86) ; 1$ & 2.46 (1.88); 1 & 2.40 (1.95); 1 & $2.67(2.08) ; 2$ \\
\hline $\begin{array}{l}\text { Problematic porn. } \\
\text { use }\end{array}$ & $1-7$ & $1.78(0.89) ; 1.5$ & $1.75(0.94) ; 1.5$ & $1.22(0.57) ; 1$ & $1.25(0.51) ; 1$ & $1.07(0.15) ; 1$ & 1.17 (0.29); 1 \\
\hline
\end{tabular}

$M=$ mean, $S D=$ standard deviation

${ }^{\mathrm{a}} 0=$ never, $1=$ less than 1 time per month, $2=1$ time per month, $3=2-3$ times per month, $4=1$ time per week, $5=$ many times per week, $6=1$ time per day, $7=$ many times per day

to the pre-COVID-19 levels. Still, it is important to note that adolescents during COVID-19 may have experienced varying levels of stress and negative emotions due to the pandemic and related restrictions (Duan et al., 2020; Ellis et al., 2020; Fegert et al., 2020; Racine et al., 2020) and may choose other activities to cope with these difficulties. Studies conducted during the COVID-19 pandemic documented that adolescents engaged in more online activities, including schoolwork, monitoring the latest news about the pandemic and used social media to stay in touch with friends and peers (Ellis et al., 2020; Munasinghe et al., 2020). This suggests that adolescents may engage in these activities instead of pornography use, and that these may help them cope with COVID-19-related stress. Concerning other pornography use motivations that were assessed in the present study (i.e., sexual pleasure, sexual curiosity, fantasy, lack of sexual satisfaction, and self-exploration), adolescents did not report significantly different levels of these motivations pre- vs. during COVID-19.

In sum, these results suggest that adolescents' pornography use characteristics, in general, might not have changed as significantly as it was suggested by previous findings ( $\mathrm{Li}$ et al., 2020a, b; Nelson et al., 2020) or predicted in popular media outlets (Döring, 2020). Prior studies also suggest that adolescents may use pornography out of curiosity or as an aid for masturbation, rather than a means to cope with negative emotions and stress (Arrington-Sanders et al., 2015; Bőthe et al., 2019;
Romito \& Beltramini, 2011; Ševčíková \& Daneback, 2014), and these motivations may not be impacted as profoundly by the pandemic as the coping-related motivations. Yet, substantial inter-individual variability was observed in both the initial levels and changes of pornography use frequency and motivations in boys and girls as well, suggesting that some adolescents might have had higher, whereas others might have had lower, initial pornography use frequency and motivations levels than the average, and individual changes were likely to be heterogeneous (i.e., different levels of increase, decrease, or stability might have been present for some adolescents), reinforcing the need to better understand the factors involved in adolescents' pornography use.

\section{Negligible Changes in Adolescents' Pre-COVID-19 and During COVID-19 Problematic Pornography Use}

Corroborating the findings of the only longitudinal study reporting temporal trends in PPU in adults (Grubbs et al., 2021), our results also suggested that PPU slightly decreased during the COVID-19 pandemic in boys, compared to pre-COVID-19 times. Although the latent changes models suggested that this general decrease in boys' PPU levels were significant, this change was very small on a descriptive level (i.e., when observing boys' pre-COVID-19 and during COVID-19 mean scores, the change was -0.03 on a scale from one to seven). Concerning 
Table 4 Latent change score statistics for boys

\begin{tabular}{|c|c|c|c|c|c|c|c|c|c|c|c|c|}
\hline & \multicolumn{12}{|c|}{ Without controls } \\
\hline & \multicolumn{6}{|c|}{ Initial level } & \multicolumn{6}{|l|}{ Change } \\
\hline & \multicolumn{3}{|l|}{ Mean } & \multicolumn{3}{|l|}{ Variance } & \multicolumn{3}{|l|}{ Mean } & \multicolumn{3}{|l|}{ Variance } \\
\hline & Estimate & S.E & $p$ value & Estimate & S.E & $p$ value & Estimate & S.E & $p$ value & Estimate & S.E & $p$ value \\
\hline Pornography use frequency & 3.799 & .083 & $<.001$ & 4.159 & .197 & $<.001$ & .049 & .084 & .563 & 3.193 & .315 & $<.001$ \\
\hline \multicolumn{13}{|l|}{ Pornography use motivations } \\
\hline Sexual pleasure & 4.750 & .081 & $<.001$ & 3.973 & .198 & $<.001$ & -.040 & .089 & .655 & 3.606 & .327 & $<.001$ \\
\hline Sexual curiosity & 2.317 & .062 & $<.001$ & 2.320 & .140 & $<.001$ & .105 & .074 & .158 & 2.612 & .250 & $<.001$ \\
\hline Fantasy & 2.269 & .066 & $<.001$ & 2.597 & .153 & $<.001$ & .152 & .085 & .076 & 3.525 & .300 & $<.001$ \\
\hline Lack of sexual satisfaction & 2.282 & .070 & $<.001$ & 2.967 & .173 & $<.001$ & .011 & .083 & .897 & 3.241 & .316 & $<.001$ \\
\hline Boredom avoidance & 1.824 & .057 & $<.001$ & 1.969 & .164 & $<.001$ & .122 & .079 & .122 & 3.008 & .296 & $<.001$ \\
\hline Emotional dist. and supp & 1.603 & .050 & $<.001$ & 1.491 & .161 & $<.001$ & .087 & .068 & .201 & 2.107 & .265 & $<.001$ \\
\hline Stress reduction & 1.890 & .061 & $<.001$ & 2.216 & .171 & $<.001$ & .099 & .079 & .210 & 3.027 & .300 & $<.001$ \\
\hline Self-exploration & 3.701 & .082 & $<.001$ & 4.048 & .143 & $<.001$ & -.099 & .098 & .309 & 4.637 & .336 & $<.001$ \\
\hline \multirow[t]{5}{*}{ Problematic pornography use } & 0.086 & .041 & .036 & 1.022 & .046 & $<.001$ & -.142 & .026 & $<.001$ & 0.411 & .041 & $<.001$ \\
\hline & \multicolumn{12}{|c|}{ With controls } \\
\hline & \multicolumn{6}{|c|}{ Initial level } & \multicolumn{6}{|l|}{ Change } \\
\hline & \multicolumn{3}{|l|}{ Intercept } & \multicolumn{3}{|c|}{ Residual variance } & \multicolumn{3}{|l|}{ Intercept } & \multicolumn{3}{|c|}{ Residual variance } \\
\hline & Estimate & S.E & $p$ value & Estimate & S.E & $p$ value & Estimate & S.E & $p$ value & Estimate & S.E & $p$ value \\
\hline Pornography use frequency & 3.841 & .070 & $<.001$ & 1.861 & .190 & $<.001$ & .048 & .102 & 640 & 3.028 & .282 & $<.001$ \\
\hline Pornography use motivations & & & & & & & & & & & & \\
\hline Sexual pleasure & 4.811 & .079 & $<.001$ & 2.165 & .174 & $<.001$ & -.079 & .110 & .475 & 3.544 & .326 & $<.001$ \\
\hline Sexual curiosity & 2.256 & .075 & $<.001$ & 2.122 & .131 & $<.001$ & .147 & .092 & .111 & 2.663 & .262 & $<.001$ \\
\hline Fantasy & 2.302 & .085 & $<.001$ & 2.402 & .147 & $<.001$ & .110 & .107 & .303 & 3.647 & .306 & $<.001$ \\
\hline Lack of sexual satisfaction & 2.297 & .086 & $<.001$ & 2.796 & .163 & $<.001$ & .008 & .102 & .940 & 3.334 & .328 & $<.001$ \\
\hline Boredom avoidance & 1.870 & .073 & $<.001$ & 1.878 & .154 & $<.001$ & .067 & .101 & .507 & 3.299 & .338 & $<.001$ \\
\hline Emotional dist. and supp & 1.535 & .059 & $<.001$ & 1.442 & .152 & $<.001$ & .153 & .081 & .060 & 2.486 & .349 & $<.001$ \\
\hline Stress reduction & 1.867 & .073 & $<.001$ & 2.092 & .156 & $<.001$ & .149 & .098 & .127 & 3.572 & .394 & $<.001$ \\
\hline Self-exploration & 3.702 & .092 & $<.001$ & 3.057 & .168 & $<.001$ & -.138 & .121 & .256 & 4.603 & .349 & $<.001$ \\
\hline Problematic pornography use & 0.096 & .046 & .037 & 0.844 & .044 & $<.001$ & -.110 & .034 & .001 & 0.402 & .040 & $<.001$ \\
\hline
\end{tabular}

S.E. $=$ standard error associated with the estimate

girls, the latent changes models suggested that their PPU levels significantly increased over the one-year period of the study. However, again, it needs to be noted that this change was very small on the descriptive level (i.e., when observing girls' preCOVID-19 and during COVID-19 mean scores, the change was +0.03 on a scale from one to seven). These significant changes might derive from the large sample size (i.e., with large sample sizes, even small differences turn out to be significant differences), and thus, we do not consider them as meaningful changes.

Yet, it needs to be noted that as in the case of pornography use frequency and pornography use motivations, substantial inter-individual variability was observed in both the initial levels and changes of PPU in boys and girls as well. These findings suggest that some adolescents might have had higher or lower initial PPU levels than the average. Also, individual changes were likely to be heterogeneous, suggesting that some adolescents might have experienced steeper increases or decreases in their PPU than the mean PPU changes. Thus, it may be plausible that some adolescents who might already have had problems with their pornography use before the COVID-19 pandemic might experience an increase in their PPU under such an unprecedented situation as a pandemic (Király et al., 2020; Mestre-Bach et al., 2020).

\section{Limitations and Future Directions}

The results of the present study provide preliminary answers to current concerns about whether adolescents' pornography use characteristics, including pornography use frequency, motivations, and PPU, might have changed due to the COVID-19 pandemic and related restrictions (e.g., social distancing). 
Table 5 Latent change score statistics for girls

\begin{tabular}{|c|c|c|c|c|c|c|c|c|c|c|c|c|}
\hline & \multicolumn{12}{|c|}{ Without controls } \\
\hline & \multicolumn{6}{|c|}{ Initial level } & \multicolumn{6}{|l|}{ Change } \\
\hline & \multicolumn{3}{|l|}{ Mean } & \multicolumn{3}{|l|}{ Variance } & \multicolumn{3}{|l|}{ Mean } & \multicolumn{3}{|l|}{ Variance } \\
\hline & Estimate & S.E & $p$ value & Estimate & S.E & $\overline{p \text { value }}$ & Estimate & S.E & $\overline{p \text { value }}$ & Estimate & S.E & $p$-value \\
\hline Pornography use frequency & 1.118 & .070 & $<.001$ & 2.723 & .176 & $<.001$ & .205 & .070 & .003 & 2.234 & .234 & $<.001$ \\
\hline \multicolumn{13}{|l|}{ Pornography use motivations } \\
\hline Sexual pleasure & 2.441 & .085 & $<.001$ & 3.963 & .187 & $<.001$ & .235 & .084 & .005 & 3.214 & .286 & $<.001$ \\
\hline Sexual curiosity & 1.877 & .061 & $<.001$ & 2.039 & .156 & $<.001$ & .182 & .071 & .011 & 2.422 & .242 & $<.001$ \\
\hline Fantasy & 1.672 & .056 & $<.001$ & 1.709 & .162 & $<.001$ & .048 & .066 & .461 & 2.054 & .218 & $<.001$ \\
\hline Lack of sexual satisfaction & 1.607 & .053 & $<.001$ & 1.543 & .164 & $<.001$ & .033 & .057 & .567 & 1.533 & .203 & $<.001$ \\
\hline Boredom avoidance & 1.421 & .045 & $<.001$ & 1.105 & .142 & $<.001$ & .113 & .054 & .039 & 1.310 & .178 & $<.001$ \\
\hline Emotional dist. and supp & 1.283 & .038 & $<.001$ & 0.802 & .139 & $<.001$ & .007 & .048 & .877 & 1.050 & .188 & $<.001$ \\
\hline Stress reduction & 1.349 & .043 & $<.001$ & 1.004 & .154 & $<.001$ & .001 & .052 & .988 & 1.260 & .178 & $<.001$ \\
\hline Self-exploration & 2.328 & .079 & $<.001$ & 3.441 & .183 & $<.001$ & .147 & .082 & .072 & 3.093 & .270 & $<.001$ \\
\hline \multirow[t]{5}{*}{ Problematic pornography use } & -1.956 & .061 & $<.001$ & 2.060 & .160 & $<.001$ & .442 & .041 & $<.001$ & 0.945 & .104 & $<.001$ \\
\hline & \multicolumn{12}{|c|}{ With controls } \\
\hline & \multicolumn{6}{|c|}{ Initial level } & \multicolumn{6}{|l|}{ Change } \\
\hline & \multicolumn{3}{|l|}{ Intercept } & \multicolumn{3}{|c|}{ Residual variance } & \multicolumn{3}{|l|}{ Intercept } & \multicolumn{3}{|c|}{ Residual variance } \\
\hline & Estimate & S.E & $\overline{p \text { value }}$ & Estimate & S.E & $\overline{p \text { value }}$ & Estimate & S.E & $\overline{p \text { value }}$ & Estimate & S.E & $p$-value \\
\hline Pornography use frequency & 1.116 & .070 & $<.001$ & 1.403 & .106 & $<.001$ & .153 & .082 & .063 & 2.139 & .212 & $<.001$ \\
\hline Pornography use motivations & & & & & & & & & & & & \\
\hline Sexual pleasure & 2.874 & .117 & $<.001$ & 1.751 & .137 & $<.001$ & .118 & .144 & .412 & 3.217 & .316 & $<.001$ \\
\hline Sexual curiosity & 2.171 & .105 & $<.001$ & 1.422 & .120 & $<.001$ & -.090 & .129 & .486 & 2.435 & .260 & $<.001$ \\
\hline Fantasy & 1.945 & .094 & $<.001$ & 1.277 & .125 & $<.001$ & -.175 & .112 & .116 & 2.180 & .246 & $<.001$ \\
\hline Lack of sexual satisfaction & 1.934 & .104 & $<.001$ & 1.220 & .126 & $<.001$ & -.088 & .114 & .438 & 1.465 & .193 & $<.001$ \\
\hline Boredom avoidance & 1.608 & .084 & $<.001$ & 0.962 & .118 & $<.001$ & .091 & .085 & .286 & 1.312 & .180 & $<.001$ \\
\hline Emotional dist. and supp & 1.420 & .077 & $<.001$ & 0.717 & .116 & $<.001$ & -.068 & .093 & .461 & 1.197 & .258 & $<.001$ \\
\hline Stress reduction & 1.598 & .081 & $<.001$ & 0.830 & .116 & $<.001$ & -.104 & .102 & .308 & 1.326 & .195 & $<.001$ \\
\hline Self-exploration & 2.788 & .121 & $<.001$ & 1.816 & .136 & $<.001$ & -.091 & .132 & .489 & 3.016 & .295 & $<.001$ \\
\hline Problematic pornography use & -1.902 & .070 & $<.001$ & 1.421 & .115 & $<.001$ & .416 & .055 & $<.001$ & 0.081 & .092 & $<.001$ \\
\hline
\end{tabular}

S.E. $=$ standard error associated with the estimate

Nevertheless, some limitations of this study need to be noted. We used data from a self-selected sample of adolescents, who completed self-report measures. Thus, the findings may include some biases (e.g., recall bias, under- or over-reporting, or selective loss of participants; Štulhofer et al., 2021). Although moral incongruence toward pornography use may be associated with self-perceived PPU (Grubbs \& Perry, 2019; Grubbs et al., 2019a, b, c), it was not assessed in this study. The present study only assessed intentional pornography use; unwanted exposure was not examined. We used a diverse sample in terms of gender and sexual orientation, but it was not representative of all adolescents in the country, limiting the findings' generalizability. The fact that our sample included adolescents from a Western, educated, industrialized, rich, and democratic (WEIRD) country also limits the generalizability of the findings. Future studies are needed to replicate and extend the present study's findings, preferably in pre-registered study designs, including non-WEIRD samples (Klein et al., 2021).

As is usually the case in large-scale and longitudinal studies among adolescents (Kohut et al., 2021; Vandenbosch \& Peter, 2016; Vandenbosch et al., 2015), we had to reduce the number of items per construct. Therefore, although we assessed a diverse set of pornography use characteristics, each motivation (Bőthe et al., 2021a) and pornography use frequency were measured by one item that may bias findings. Moreover, the use of self-report measures to assess motivations may introduce biases (e.g., it is not possible to differentiate between reports of actual motivations and posterior attributions concerning the reasons of given behaviors). Thus, study designs focusing on real-time data collection when a behavior occurs 
(e.g., ecological momentary assessment, EMA) might provide a more accurate and nuanced understanding of motivations underlying pornography use. Given the presence of substantial inter-individual variability in the latent change models, future studies would do well in relying on an analytic approach that is able to identify subpopulations of adolescents characterized by different change scores. Lastly, while no differences were observed in the results concerning boys' pornography use with and without the included control variables, most of the minimal increases in girls' pornography use disappeared when control variables were added. These results highlight the importance of considering potential confounding variables when examining pornography use, though the selection of these potential control variables requires careful consideration and justification (Wright, 2021), and results should be preferably reported with and without the control variables for full transparency.

\section{Conclusions}

Although prior cross-sectional studies reported a self-perceived increase in adolescents and young adults' pornography use since the beginning of the COVID-19 pandemic, our longitudinal results suggest that adolescents during the pandemic might not use pornography more frequently and not use pornography for different reasons compared to prior to their pandemic levels. Although a slight decrease in boys' PPU, and a slight increase in girls' PPU were observed, these changes could be considered negligible with little practical or clinical relevance (Ferguson, 2016; Sawilowsky, 2009). Despite previous propositions, concerns, and cross-sectional findings (Awan et al., 2021; Mestre-Bach et al., 2020; NebotGarcia et al., 2020; Nelson et al., 2020), longitudinal results suggest that the COVID-19 pandemic and related lockdowns might not have led to general increases in adolescents and adults' (Grubbs et al., 2021) pornography use.

Supplementary Information The online version contains supplementary material available at https://doi.org/10.1007/s10508-021-02282-4.

Acknowledgements The authors would like to thank Mylène Desrosiers and Camélia Dubois for their assistance with data collection.

Author Contributions Conceptualization: BB, M-PV-M, JD, M-MP, MM-P, SB. Methodology: BB, M-PV-M, JD, IT-K, SB. Formal analysis: BB, IT-K. Investigation: BB, M-PV-M, JD, M-MP, MM-P, IT-K, SB. Writing —original draft preparation: BB, M-MP, MM-P, IT-K. Writing-review and editing: M-PV-M, JD, SB. Funding acquisition: BB, JD, SB. Resources: JD, SB. Supervision: M-PV-M, SB.

Funding B. Bôthe was supported by the Merit Scholarship Program for Foreign Students (PBEEE) awarded by the Ministère de l'Éducation et de l'Enseignement Supérieur (MEES) and by a postdoctoral fellowship from the SCOUP Team - Sexuality and Couples - Fonds de recherche du Québec, Société et Culture. This work was supported by a grant from the Canadian Institutes of Health Research awarded to S. Bergeron and J. Dion.

\section{Declarations}

Conflict of interest The authors declare that they have no conflict of interest.

Informed Consent Informed consent was obtained from all individual participants included in the study.

Human and Animal Participants All procedures performed in the study involving human participants were in accordance with the ethical standards of the institutional research committee of the Université de Montréal and the Université du Québec à Chicoutimi, and with the 1964 Helsinki declaration and its later amendments or comparable ethical standards.

\section{References}

Arrington-Sanders, R., Harper, G. W., Morgan, A., Ogunbajo, A., Trent, M., \& Fortenberry, J. D. (2015). The role of sexually explicit material in the sexual development of same-sex-attracted black adolescent males. Archives of Sexual Behavior, 44(3), 597-608. https:// doi.org/10.1007/s10508-014-0416-x

Awan, H. A., Aamir, A., Diwan, M. N., Ullah, I., Pereira-Sanchez, V., Ramalho, R., Orsolini, L., de Filippis, R., Ojeahere, M. I., Ransing, R., Vadsaria, A. K., \& Virani, S. (2021). Internet and pornography use during the COVID-19 pandemic: Presumed impact and what can be done. Frontiers in Psychiatry, 12. https://doi.org/10.3389/ FPSYT.2021.623508

Bauer, G. R., Braimoh, J., Scheim, A. I., \& Dharma, C. (2017). Transgender-inclusive measures of sex/gender for population surveys: Mixed methods evaluation and recommendations. PLoS ONE, 12(5). https://doi.org/10.1371/journal.pone.0178043

Bőthe, B., Tóth-Király, I., Bella, N., Potenza, M. N., Demetrovics, Z., \& Orosz, G. (2021a). Why do people watch pornography? The motivational basis of pornography use. Psychology of Addictive Behaviors, 35(2), 172-186. https://doi.org/10.1037/adb0000603

Bőthe, B., Tóth-Király, I., Demetrovics, Z., \& Orosz, G. (2021b). The short version of the Problematic Pornography Consumption Scale (PPCS-6): A reliable and valid measure in general and treatmentseeking populations. Journal of Sex Research, 58(3), 342-352. https://doi.org/10.1080/00224499.2020.1716205

Bőthe, B., Tóth-Király, I., Potenza, M. N., Orosz, G., \& Demetrovics, Z. (2020a). High-frequency pornography use may not always be problematic. Journal of Sexual Medicine, 17(4), 793-811. https:// doi.org/10.1016/j.jsxm.2020.01.007

Bőthe, B., Tóth-Király, I., Zsila, Á., Griffiths, M. D., Demetrovics, Z., \& Orosz, G. (2018). The development of the Problematic Pornography Consumption Scale (PPCS). Journal of Sex Research, 55(3), 395-406. https://doi.org/10.1080/00224499.2017.1291798

Bőthe, B., Vaillancourt-Morel, M.-P., \& Bergeron, S. (2021c). Associations between pornography use frequency, pornograpy use motivations, and sexual wellbeing in couples. Journal of Sex Research. https://doi.org/10.1080/00224499.2021.1893261

Bőthe, B., Vaillancourt-Morel, M.-P., Bergeron, S., \& Demetrovics, Z. (2019). Problematic and non-problematic pornography use among LGBTQ adolescents: A systematic literature review. Current Addiction Reports, 6(4), 478-494. https://doi.org/10.1007/ s40429-019-00289-5

Bőthe, B., Vaillancourt-Morel, M.-P., Dion, J., Štulhofer, A., \& Bergeron, S. (2021d). Validity and reliability of the short version of the Problematic Pornography Consumption Scale (PPCS-6-A) in adolescents. Psychology of Addictive Behaviors, 35(4), 486-500. 
Bőthe, B., Vaillancourt-Morel, M.-P., Girouard, A., Štulhofer, A., Dion, J., \& Bergeron, S. (2020b). A large-scale comparison of Canadian sexual/gender minority and heterosexual, cisgender adolescents' pornography use characteristics. Journal of Sexual Medicine, 17(6), 1156-1167. https://doi.org/10.1016/j.jsxm.2020.02.009

Campbell, L., \& Kohut, T. (2017). The use and effects of pornography in romantic relationships. Current Opinion in Psychology, 13, 6-10. https://doi.org/10.1016/j.copsyc.2016.03.004

Chen, F. F. (2007). Sensitivity of goodness of fit indexes to lack of measurement invariance. Structural Equation Modeling, 14(3), 464-504. https://doi.org/10.1080/10705510701301834

Cheung, G. W., \& Rensvold, R. B. (2002). Evaluating goodness-of-fit indexes for testing measurement invariance. Structural Equation Modeling, 9(2), 233-255.

Döring, N. (2020). How is the COVID-19 pandemic affecting our sexualities? An overview of the current media narratives and research hypotheses [Commentary]. Archives of Sexual Behavior, 49(8), 2765-2778. https://doi.org/10.1007/s10508-020-01790-Z

Duan, L., Shao, X., Wang, Y., Huang, Y., Miao, J., Yang, X., \& Zhu, G. (2020). An investigation of mental health status of children and adolescents in china during the outbreak of COVID-19. Journal of Affective Disorders, 275, 112-118. https://doi.org/10.1016/j. jad.2020.06.029

Efrati, Y. (2020). Problematic and non-problematic pornography use and compulsive sexual behaviors among understudied populations: Children and adolescents. Current Addiction Reports, 7(1), 68-75. https://doi.org/10.1007/s40429-020-00300-4

Efrati, Y., \& Dannon, P. (2019). Normative and clinical self-perceptions of sexuality and their links to psychopathology among adolescents. Psychopathology, 51(6), 380-389.

Efrati, Y., \& Gola, M. (2018). Understanding and predicting profiles of compulsive sexual behavior among adolescents. Journal of Behavioral Addictions, 7(4), 1004-1014. https://doi.org/10.1556/2006.7. 2018.100

Ellis, W. E., Dumas, T. M., \& Forbes, L. M. (2020). Physically isolated but socially connected: Psychological adjustment and stress among adolescents during the initial COVID-19 crisis. Canadian Journal of Behavioural Science, 52(3), 177-187. https://doi.org/10.1037/ cbs0000215

Fegert, J. M., Vitiello, B., Plener, P. L., \& Clemens, V. (2020). Challenges and burden of the Coronavirus 2019 (COVID-19) pandemic for child and adolescent mental health: A narrative review to highlight clinical and research needs in the acute phase and the long return to normality. Child and Adolescent Psychiatry and Mental Health, 14(1). https://doi.org/10.1186/s13034-020-00329-3

Ferguson, C. J. (2016). An effect size primer: A guide for clinicians and researchers. In A. E. Kazdin (Ed.), Methodological issues and strategies in clinical research (4th ed.). (pp. 301-310). American Psychological Association. https://doi.org/10.1037/14805-020

Findlay, L., \& Arim, R. (2020). Canadians report lower self-perceived mental health during the COVID-19 pandemic. www.statcan.gc.ca

Finney, S. J., \& DiStefano, C. (2013). Non-normal and categorical data in structural equation modeling. In G. R. Hancock \& R. O. Mueller (Eds.), Structural equation modeling: A second course (2nd ed., pp. 439-492). Information Age Publishing.

Griffiths, M. D. (2005). A "components" model of addiction within a biopsychosocial framework. Journal of Substance Use, 10(4), 191-197. https://doi.org/10.1080/14659890500114359

Grubbs, J. B., \& Perry, S. L. (2019). Moral incongruence and pornography use: A critical review and integration. Journal of Sex Research, 56(1), 29-37. https://doi.org/10.1080/00224499.2018. 1427204

Grubbs, J. B., Hoagland, C., Lee, B., Grant, J., Davison, P. M., Reid, R., \& Kraus, S. W. (2020). Sexual addiction 25 years on: A systematic and methodological review of empirical literature and an agenda for future research. Clinical Psychology Review. https://doi.org/10.1016/j.cpr.2020.101925

Grubbs, J. B., Kraus, S. W., \& Perry, S. L. (2019a). Self-reported addiction to pornography in a nationally representative sample: The roles of use habits, religiousness, and moral incongruence. Journal of Behavioral Addictions, 8(1), 88-93.

Grubbs, J. B., Perry, S. L., Kraus, S. W., \& Weinandy, J. T. (2021). Porndemic? A longitudinal study of pornography use before and during the COVID-19 pandemic in a nationally representative sample of Americans. Archives of Sexual Behavior. https://doi.org/10.1007/ s10508-021-02077-7

Grubbs, J. B., Perry, S. L., Wilt, J. A., \& Reid, R. C. (2019b). Pornography problems due to moral incongruence: An integrative model with a systematic review and meta-analysis. Archives of Sexual Behavior, 48(2), 397-415. https://doi.org/10.1007/ s10508-018-1248-X

Grubbs, J. B., Wright, P. J., Braden, A. L., Wilt, J. A., \& Kraus, S. W. (2019c). Internet pornography use and sexual motivation: A systematic review and integration. Annals of the International Communication Association, 43(2), 117-155. https://doi.org/10. 1080/23808985.2019.1584045

Guessoum, S. B., Lachal, J., Radjack, R., Carretier, E., Minassian, S., Benoit, L., \& Moro, M. R. (2020). Adolescent psychiatric disorders during the COVID-19 pandemic and lockdown. Psychiatry Research, 291. https://doi.org/10.1016/j.psychres.2020.113264

Herbenick, D., Fu, T.-C., Wright, P., Paul, B., Gradus, R., Bauer, J., \& Jones, R. (2020). Diverse sexual behaviors and pornography use: Findings from a nationally representative probability survey of Americans aged 14 to 60 years. Journal of Sexual Medicine, 17, 623-633. https://doi.org/10.1016/j.jsxm.2020.01.013

Islam, S. M. D. U., Bodrud-Doza, M., Khan, R. M., Haque, M. A., \& Mamun, M. A. (2020). Exploring COVID-19 stress and its factors in Bangladesh: A perception-based study. Heliyon, 6(7). https:// doi.org/10.1016/j.heliyon.2020.e04399

Kahn, A. S., Ratan, R., \& Williams, D. (2014). Why we distort in selfreport: Predictors of self-report errors in video game play. Journal of Computer-Mediated Communication, 19(4), 1010-1023. https:// doi.org/10.1111/jcc4.12056

Király, O., Potenza, M. N., Stein, D. J., King, D. L., Hodgins, D. C., Saunders, J. B., Griffiths, M. D., Gjoneska, B., Billieux, J., Brand, M., Abbott, M. W., Chamberlain, S. R., Corazza, O., Burkauskas, J., Sales, C. M. D., Montag, C., Lochner, C., Grünblatt, E., Wegmann, E., \& Demetrovics, Z. (2020). Preventing problematic internet use during the COVID-19 pandemic: Consensus guidance. Comprehensive Psychiatry, 100. https://doi.org/10.1016/j.compp sych.2020.152180

Klein, V., Savaş, Ö., \& Conley, T. D. (2021). How WEIRD and androcentric is sex research? Global inequities in study populations. Journal of Sex Research. https://doi.org/10.1080/00224499.2021. 1918050

Kohut, T., \& Štulhofer, A. (2018). The role of religiosity in adolescents' compulsive pornography use: A longitudinal assessment. Journal of Sex and Marital Therapy, 44(8), 759-775.

Kohut, T., Balzarini, R. N., Fisher, W. A., \& Campbell, L. (2018). Pornography's associations with open sexual communication and relationship closeness vary as a function of dyadic patterns of pornography use within heterosexual relationships. Journal of Social and Personal Relationships, 35(4), 655-676. https://doi. org/10.1177/0265407517743096

Kohut, T., Balzarini, R. N., Fisher, W. A., Grubbs, J. B., Campbell, L., \& Prause, N. (2020). Surveying pornography use: A shaky science resting on poor measurement foundations. Journal of Sex Research, 57(6), 722-742. https://doi.org/10.1080/00224499. 2019.1695244

Kohut, T., Landripet, I., \& Štulhofer, A. (2021). Testing the confluence model of the association between pornography use and male sexual 
aggression: A longitudinal assessment in two independent adolescent samples from Croatia. Archives of Sexual Behavior, 50(2), 647-665. https://doi.org/10.1007/s10508-020-01824-6

Kraus, S. W., \& Sweeney, P. J. (2019). Hitting the target: Considerations for differential diagnosis when treating individuals for problematic use of pornography. Archives of Sexual Behavior, 48(2), 431-435.

Kraus, S. W., Krueger, R. B., Briken, P., First, M. B., Stein, D. J., Kaplan, M. S., Voon, V., Abdo, C. H. N. N., Grant, J. E., Atalla, E., \& Reed, G. M. (2018). Compulsive sexual behaviour disorder in the ICD-11. World Psychiatry, 17(1), 109-110.

Kraus, S. W., Gola, M., Grubbs, J. B., Kowalewska, E., Hoff, R. A., Lew-Starowicz, M., Martino, S., Shirk, S. D., \& Potenza, M. N. (2020). Validation of a brief pornography screen across multiple samples. Journal of Behavioral Addictions, 9(2), 259-271. https:// doi.org/10.1556/2006.2020.00038

Lehmiller, J. J., Garcia, J. R., Gesselman, A. N., \& Mark, K. P. (2021). Less sex, but more sexual diversity: Changes in sexual behavior during the COVID-19 coronavirus pandemic. Leisure Sciences, 43(1-2), 295-304. https://doi.org/10.1080/01490400.2020.17740 16

Lewczuk, K., Glica, A., Nowakowska, I., Gola, M., \& Grubbs, J. B. (2020). Evaluating pornography problems due to moral incongruence model. Journal of Sexual Medicine, 17(2), 300-311. https:// doi.org/10.1016/j.jsxm.2019.11.259

Li, G., Tang, D., Song, B., Wang, C., Qunshan, S., Xu, C., Geng, H., Wu, H., He, X., \& Cao, Y. (2020a). Impact of the COVID-19 pandemic on partner relationships and sexual and reproductive health: Cross-sectional, online survey study. Journal of Medical Internet Research, 22(8). https://doi.org/10.2196/20961

Li, W., Li, G., Xin, C., Wang, Y., \& Yang, S. (2020b). Changes in sexual behaviors of young women and men during the coronavirus disease 2019 outbreak: A convenience sample from the epidemic area. Journal of Sexual Medicine, 17, 1225-1228. https://doi.org/10. 1016/j.jsxm.2020.04.380

Lobe, B., Livingstone, S., Ólafsson, K., \& Vodeb, H. (2011). Crossnational comparison of risks and safety on the internet: Initial analysis from the EU Kids Online survey of European children.

Marsh, H. W., Hau, K.-T., \& Grayson, D. (2005). Goodness of fit evaluation in structural equation modeling. In A. Maydeu-Olivares \& J. McArdle (Eds.), Contemporary psychometrics (pp. 275-340) Erlbaum.

Marsh, H. W. (2007). Application of confirmatory factor analysis and structural equation modeling in sport and exercise psychology. In G. Tenenbaum \& R. C. Eklund (Eds.), Handbook of sport psychology (Third ed.) (pp. 774-798). Wiley.

Mazza, C., Ricci, E., Biondi, S., Colasanti, M., Ferracuti, S., Napoli, C., \& Roma, P. (2020). A nationwide survey of psychological distress among italian people during the COVID-19 pandemic: Immediate psychological responses and associated factors. International Journal of Environmental Research and Public Health, 17(9), 1-14. https://doi.org/10.3390/ijerph17093165

McArdle, J. J. (2008). Latent variable modeling of differences and changes with longitudinal data. Annual Review of Psychology, 60, 577-605. https://doi.org/10.1146/ANNUREV.PSYCH.60. 110707.163612

McDonald, R. P. (1970). The theoretical foundations of principal factor analysis, canonical factor analysis, and alpha factor analysis. British Journal of Mathematical and Statistical Psychology, 23(1), 1-21. https://doi.org/10.1111/j.2044-8317.1970.tb00432.x

McElhaney, K. B., Allen, J. P., Stephenson, J. C., \& Hare, A. L. (2009). Attachment and autonomy during adolescence. In R. M. Lerner \& L. Steinberg (Eds.), Handbook of adolescent psychology (pp. 358-403). Wiley. https://doi.org/10.1002/9780470479193.adlps y001012

Mestre-Bach, G., Blycker, G. R., \& Potenza, M. N. (2020). Pornography use in the setting of the COVID-19 pandemic. Journal of
Behavioral Addictions, 9(2), 181-183. https://doi.org/10.1556/ 2006.2020.00015

Millsap, P. (2011). Statistical approaches to measurement invariance. Taylor \& Francis.

Morin, A. J. S., Boudrias, J.-S., Marsh, H. W., McInerney, D. M., Dagenais-Desmarais, V., Madore, I., \& Litalien, D. (2016). Complementary variable-and person-centered approaches to the dimensionality of psychometric constructs: Application to psychological wellbeing at work. Journal of Business and Psychology, 32(4), 395-419. https://doi.org/10.1007/S10869-016-9448-7

Morin, A. J. S., Myers, N. D., \& Lee, S. (2019). Modern factor analytic techniques: Bifactor models, exploratory structural equation modeling (ESEM) and bifactor-ESEM. In G. Tenenbaum \& R. C. Eklund (Eds.), Handbook of sport psychology (4th ed.) (pp. 1044-1073). Wiley.

Munasinghe, S., Sperandei, S., Freebairn, L., Conroy, E., Jani, H., Marjanovic, S., \& Page, A. (2020). The impact of physical distancing policies during the COVID-19 pandemic on health and well-being among Australian adolescents. Journal of Adolescent Health, 67(5), 653-661. https://doi.org/10.1016/j.jadohealth.2020.08.008

Muthén, L. K., \& Muthén, B. O. (2018). Mplus user guide. Author.

Nebot-Garcia, J. E., Ruiz-Palomino, E., Giménez-García, C., Gil-Llario, M. D., \& Ballester-Arnal, R. (2020). Sexual frequency of Spanish adolescents during confinement by COVID-19. Revista de Psicologia Clinica Con Ninos y Adolescentes, 7(3), 16-26. https://doi. org/10.21134/rpcna.2020.mon.2038

Nelson, K. M., Gordon, A. R., John, S. A., Stout, C. D., \& Macapagal, K. (2020). "Physical sex is over for now": Impact of COVID-19 on the well-being and sexual health of adolescent sexual minority males in the U.S. Journal of Adolescent Health, 67(6), 756-762. https://doi.org/10.1016/j.jadohealth.2020.08.027

Oosterhoff, B., Palmer, C. A., Wilson, J., \& Shook, N. (2020). Adolescents' motivations to engage in social distancing during the COVID-19 pandemic: Associations with mental and social health. Journal of Adolescent Health, 67(2), 179-185. https://doi.org/10. 1016/j.jadohealth.2020.05.004

Oosterhoff, B., \& Palmer, C. (2020). Psychological correlates of news monitoring, social distancing, disinfecting, and hoarding behaviors among US adolescents during the COVID-19 pandemic (pp. 1-20). PsyArXiv. https://doi.org/10.31234/osf.io/rpcy4

Owens, E. W., Behun, R. J., Manning, J. C., \& Reid, R. C. (2012). The impact of internet pornography on adolescents: A review of the research. Sexual Addiction and Compulsivity, 19(1-2), 99-122. https://doi.org/10.1080/10720162.2012.660431

Perry, S. L. (2019). Is the link between pornography use and relational happiness really more about masturbation? Results from two national surveys. Journal of Sex Research, 57(1), 1-13. https:// doi.org/10.1080/00224499.2018.1556772

Peter, J., \& Valkenburg, P. M. (2016). Adolescents and pornography: A review of 20 years of research. Journal of Sex Research, 53(4-5), 509-531. https://doi.org/10.1080/00224499.2016.1143441

Pizzol, D., Bertoldo, A., \& Foresta, C. (2016). Adolescents and web porn: A new era of sexuality. International Journal of Adolescent Medicine and Health, 28(2), 169-173.

Pornhub.com. (2020a). Coronavirus Canada. https://www.pornhub. com/insights/canada-coronavirus

Pornhub.com. (2020b). Coronavirus Update-June 18. https://www. pornhub.com/insights/coronavirus-update-june- 18

Prause, N. (2019). Porn is for masturbation [Commentary]. Archives of Sexual Behavior, 48(8), 2271-2277. https://doi.org/10.1007/ s10508-019-1397-6

Price, J., Patterson, R., Regnerus, M., \& Walley, J. (2016). How much more $\mathrm{XXX}$ is generation $\mathrm{X}$ consuming? Evidence of changing attitudes and behaviors related to pornography since 1973. Journal of Sex Research, 53(1), 12-20. https://doi.org/10.1080/00224499. 2014.1003773 
Racine, N., Cooke, J. E., Eirich, R., Korczak, D. J., McArthur, B. A., \& Madigan, S. (2020). Child and adolescent mental illness during COVID-19: A rapid review. Psychiatry Research, 292, 1-3. https:// doi.org/10.1016/j.psychres.2020.113307

Reid, R. C., Li, D. S., Gilliland, R., Stein, J. A., \& Fong, T. (2011). Reliability, validity, and psychometric development of the pornography consumption inventory in a sample of hypersexual men. Journal of Sex and Marital Therapy, 37(5), 359-385.

Romito, P., \& Beltramini, L. (2011). Watching pornography: Gender differences, violence and victimization. An exploratory study in Italy. Violence against Women, 17(10), 1313-1326. https://doi.org/ $10.1177 / 1077801211424555$

Rousseau, A., Bőthe, B., \& Štulhofer, A. (2021). Theoretical antecedents of male adolescents' problematic pornography use: A longitudinal assessment. Journal of Sex Research, 58, 331-341.

Salari, N., Hosseinian-Far, A., Jalali, R., Vaisi-Raygani, A., Rasoulpoor, S. S., Mohammadi, M., Rasoulpoor, S. S., \& Khaledi-Paveh, B. (2020). Prevalence of stress, anxiety, depression among the general population during the COVID-19 pandemic: A systematic review and meta-analysis. Globalization and Health, 16(1), 1-11. https:// doi.org/10.1186/s12992-020-00589-w

Sawilowsky, S. S. (2009). New effect size rules of thumb. Journal of Modern Applied Statistical Methods, 8(2), 597-599. https://doi. org/10.22237/jmasm/1257035100

Ševčíková, A., \& Daneback, K. (2014). Online pornography use in adolescence: Age and gender differences. European Journal of Developmental Psychology, 11(6), 674-686. https://doi.org/10. 1080/17405629.2014.926808

Skrondal, A., \& Laake, P. (2001). Regression among factor scores. Psychometrika, 66(4), 563-575.

Smetana, J. G., Campione-Barr, N., \& Metzger, A. (2006). Adolescent development in interpersonal and societal contexts. Annual Review of Psychology, 57, 255-284. https://doi.org/10.1146/annur ev.psych.57.102904.190124

Štulhofer, A., Rousseau, A., \& Shekarchi, R. (2020). A two-wave assessment of the structure and stability of self-reported problematic pornography use among male Croatian adolescents. International Journal of Sexual Health, 32(2), 151-164. https://doi.org/10.1080/ 19317611.2020.1765940

Štulhofer, A., Landripet, I., Matković, T., Koletić, G., Kohut, T., Buško, V., \& Vodopijevec, A. (2021). Are we losing the most relevant cases first? Selective dropout in two independent panels of Croatian adolescents (the PROBIOPS study). Archives of Sexual Behavior, 50, 2215-2216.

Svedin, C. G., Åkerman, I., \& Priebe, G. (2011). Frequent users of pornography. A population based epidemiological study of Swedish male adolescents. Journal of Adolescence, 34(4), 779-788. https:// doi.org/10.1016/j.adolescence.2010.04.010

Thomas, K. A., \& Clifford, S. (2017). Validity and Mechanical Turk: An assessment of exclusion methods and interactive experiments. Computers in Human Behavior, 77, 184-197. https://doi.org/10. 1016/j.chb.2017.08.038

Tóth-Király, I., Morin, A. J. S., \& Salmela-Aro, K. (2021). A longitudinal perspective on the associations between work engagement and workaholism. Work \& Stress, 35(1), 27-56. https://doi.org/10. 1080/02678373.2020.1801888
Vaillancourt-Morel, M.-P., Blais-Lecours, S., Labadie, C., Bergeron, S., Sabourin, S., \& Godbout, N. (2017). Profiles of cyberpornography use and sexual well-being in adults. Journal of Sexual Medicine, 14(1), 78-85. https://doi.org/10.1016/j.jsxm.2016.10.016

Vandenbosch, L., \& Peter, J. (2016). Antecedents of the initiation of watching sexually explicit internet material: A longitudinal study among adolescents. Mass Communication and Society, 19(4), 499-521. https://doi.org/10.1080/15205436.2016.1148171

Vandenbosch, L., van Oosten, J. M. F., \& Peter, J. (2015). The relationship between sexual content on mass media and social media: A longitudinal study. Cyberpsychology, Behavior, and Social Networking, 18(12), 697-703. https://doi.org/10.1089/cyber.2015. 0197

Wang, C., Pan, R., Wan, X., Tan, Y., Xu, L., McIntyre, R. S., Choo, F. N., Tran, B., Ho, R., Sharma, V. K., \& Ho, C. (2020). A longitudinal study on the mental health of general population during the COVID-19 epidemic in China. Brain, Behavior, and Immunity, 87, 40-48. https://doi.org/10.1016/j.bbi.2020.04.028

Weinrich, J. D. (2014). On the design, development, and testing of sexual identity questions: A discussion and analysis of Kristen Miller and J. Michael Ryan's work for the national health interview survey. Journal of Bisexuality, 14, 502-523.

Wéry, A., \& Billieux, J. (2016). Online sexual activities: An exploratory study of problematic and non-problematic usage patterns in a sample of men. Computers in Human Behavior, 56, 257-266. https://doi.org/10.1016/j.chb.2015.11.046

Wolak, J., Mitchell, K., \& Finkelhor, D. (2007). Unwanted and wanted exposure to online pornography in a national sample of youth Internet users. Pediatrics, 119(2), 247-257. https://doi.org/10.1542/ peds.2006-1891

World Health Organization. (2020). Mental health and psychosocial considerations during the COVID-19 outbreak (pp. 1-6). https:// www.who.int/docs/default-source/coronaviruse/mental-healthconsiderations.pdf.

Wright, P. J. (2021). Overcontrol in pornography research: Let it go, let it go... [Letter to the Editor]. Archives of Sexual Behavior, 50(2), 387-392. https://doi.org/10.1007/s10508-020-01902-9

Wright, P. J., Herbenick, D., \& Paul, B. (2020). Adolescent condom use, parent-adolescent sexual health communication, and pornography: Findings from a U.S. probability sample. Health Communication, 35(13), 1576-1582. https://doi.org/10.1080/10410236.2019.16523 92

Zattoni, F., Gül, M., Soligo, M., Morlacco, A., Motterle, G., Collavino, J., Celeste, A., Marco, B., Fabrizio, M., \& Moro, D. (2020). The impact of COVID-19 pandemic on pornography habits: A global analysis of Google Trends. International Journal of Impotence Research. https://doi.org/10.1038/s41443-020-00380-w

Publisher's Note Springer Nature remains neutral with regard to jurisdictional claims in published maps and institutional affiliations. 